OPEN ACCESS

Edited by:

Feng Li,

Huazhong Agricultural University,

China

Reviewed by:

Michael Wassenegger,

RLP AgroScience, Germany

Yi Li,

Peking University, China

Xian-Bing Wang,

China Agricultural University, China

*Correspondence:

Cheng-Guo Duan

duancg@purdue.edu

Hui-Shan Guo

guohs@im.ac.cn

${ }^{\dagger}$ Present Address:

Cheng-Guo Duan,

Department of Horticulture and

Landscape Architecture, Purdue University, West Lafayette, IN, USA

FThese authors have contributed equally to this work.

Specialty section:

This article was submitted to

Virology,

a section of the journal

Frontiers in Microbiology

Received: 20 July 2016 Accepted: 11 August 2016 Published: 24 August 2016

Citation:

Fang Y-Y, Zhao J-H, Liu S-W, Wang S,

Duan C-G and Guo H-S (2016) CMV2b-AGO Interaction Is Required for the Suppression of RDR-Dependent Antiviral Silencing in Arabidopsis. Front. Microbiol. 7:1329.

doi: 10.3389/fmicb.2016.01329

\section{CMV2b-AGO Interaction Is Required for the Suppression of RDR-Dependent Antiviral Silencing in Arabidopsis}

\author{
Yuan-Yuan Fang ${ }^{1 \neq}$, Jian-Hua Zhao ${ }^{1 \neq}$, Shang-Wu Liu ${ }^{1,2}$, Sheng Wang ${ }^{1}$, Cheng-Guo Duan ${ }^{1 * \dagger}$ \\ and Hui-Shan Guo ${ }^{1,3 *}$ \\ ${ }^{1}$ State Key Laboratory of Plant Genomics, Institute of Microbiology, Chinese Academy of Sciences, Beijing, China, \\ ${ }^{2}$ Virus-free Seedling Research Institute, Heilongjiang Academy of Agricultural Sciences, Harbin, China, ${ }^{3}$ College of Life \\ Sciences, University of Chinese Academy of Sciences, Beijing, China
}

Using a transient plant system, it was previously found that the suppression of Cucumber mosaic virus (CMV) 2b protein relies on its double-strand (ds) RNA binding capacity, but it is independent of its interaction with ARGONAUTE (AGO) proteins. Thus, the biological meaning of the $2 \mathrm{~b}-\mathrm{AGO}$ interaction in the context of virus infection remains elusive. In this study, we created infectious clones of CMV mutants that expressed the $2 \mathrm{~b}$ functional domains of dsRNA or AGO binding and tested the effect of these CMV mutants on viral pathogenicity. We found that the mutant $C M V 2 b_{(1-76)}$ expressing the $2 \mathrm{~b}$ dsRNA-binding domain exhibited the same virulence as wild-type CMV in infection with either wild-type Arabidopsis or rdr1/6 plants with RDR1- and RDR6-deficient mutations. However, remarkably reduced viral RNA levels and increased virus (v)siRNAs were detected in $\mathrm{CMV} 2 \mathrm{~b}_{(1-76)}$-infected Arabidopsis in comparison to CMV infection, which demonstrated that the $2 \mathrm{~b}_{(1-76)}$ deleted AGO-binding domain failed to suppress the RDR1/RDR6-dependent degradation of viral RNAs. The mutant CMV2 $\mathrm{b}_{(8-111)}$ expressing mutant $2 \mathrm{~b}$, in which the $\mathrm{N}$-terminal 7 amino acid (aa) was deleted, exhibited slightly reduced virulence, but not viral RNA levels, in both wild-type and rdr1/6 plants, which indicated that $2 \mathrm{~b}$ retained the AGO-binding activity acquired the counter-RDRs degradation of viral RNAs. The deletion of the N-terminal 7 aa of $2 b$ affected virulence due to the reduced affinity for long dsRNA. The mutant $C M V 2 b_{(18-111)}$ expressing mutant $2 \mathrm{~b}$ lacked the N-terminal 17 aa but retained its AGO-binding activity greatly reduced virulence and viral RNA level. Together with the instability of both $2 b_{(18-111)}$-EGFP and RFP-AGO4 proteins when co-expressed in Nicotiana benthamiana leaves, our data demonstrates that the effect of $2 \mathrm{~b}-\mathrm{AGO}$ interaction on counter-RDRs antiviral defense required the presence of $2 \mathrm{~b}$ dsRNA-binding activity. Taken together, our findings demonstrate that the dsRNA-binding activity of the $2 b$ was essential for virulence, whereas the 2b-AGO interaction was necessary for interference with RDR1/6-dependent antiviral silencing in Arabidopsis.

Keywords: CMV, viral suppressor, 2b, ARGONAUTE, RDR, RNA silencing 


\section{INTRODUCTION}

RNA silencing (RNA interference, RNAi) is an evolutionarily conserved regulatory mechanism of gene expression in eukaryotes mediated by 20-25-nucleotides (nt) small interference RNAs (siRNAs; Meister and Tuschl, 2004; Baulcombe, 2005). These siRNAs are processed from doublestranded (ds) or hairpin (hp) RNA by Dicer or Dicer-like (DCL) protein. To induce silencing, one strand of a siRNA is loaded into an Argonaute (AGO) protein to form the RNA-induced silencing complex (RISC) and guides the RISC to bind to complementary single-stranded RNA and cleave the RNA. siRNAs-guided AGO-cleaved target RNA may be recognized by RNA-dependent RNA polymerase (RDR), which amplifies the dsRNA substrate for DCLs to produce secondary siRNAs and reinforce the RNA silencing process (Peragine et al., 2004; Axtell et al., 2006; Baulcombe, 2007).

In plants, viral infection also triggers the siRNA-mediated RNA silencing as a natural antiviral defense mechanism. RDRdependent amplification is a crucial step toward achieving an efficient antiviral defense response in plants. Two of the six Arabidopsis thaliana RDRs, RDR1, and RDR6, have been implicated in defense against many viruses, including Cucumber mosaic virus (CMV; Dalmay et al., 2000; Qu et al., 2005; Schwach et al., 2005; Vaistij and Jones, 2009; Garcia-Ruiz et al., 2010; Qu, 2010; Ying et al., 2010; Li et al., 2014).

$\mathrm{CMV}$ is a tripartite positive-strand RNA virus, which contains three genomic RNAs and two subgenomic RNAs that encode five proteins (Palukaitis and Garcia-Arenal, 2003): two RNAdependent RNA polymerases, 1a and 2a proteins, and movement protein (MP) encoded by genomic RNA1, RNA2, and RNA3. The $2 \mathrm{~b}$ protein and the coat protein $(\mathrm{CP})$ are expressed from subgenomic RNA4A and RNA4, which are transcribed from genomic RNA2 and RNA3, respectively (Schwinghamer and Symons, 1975; Ding et al., 1994). The $2 \mathrm{~b}$ protein expressed from subgenomic RNA4A plays an important role in diverse processes, including symptom induction as a viral virulence determinant, host-specific virus accumulation, the inhibition of RNA silencing and the systemic spread of silencing (Ding et al., 1995; Lucy et al., 2000; Guo and Ding, 2002; Shi et al., 2002). As a viral suppressor of RNA silencing (VSR), the $2 \mathrm{~b}$ protein has been identified to directly interact with both the long/short dsRNA and AGO proteins (Zhang et al., 2006; Goto et al., 2007; González et al., 2010, 2012; Duan et al., 2012; Hamera et al., 2012), attributed to its complex biochemical and subcellular targeting activity (Duan et al., 2012). In our previous study of the $2 \mathrm{~b}$ protein encoded by the severe SD isolate from CMV subgroup I, we uncoupled the domain requirements for dsRNA binding and nucleolar targeting from the physical interactions with AGO proteins. We found that dsRNA sequestration is the predominant mechanism by which $2 \mathrm{~b}$ suppresses silencing and that the $2 \mathrm{~b}-\mathrm{AGO}$ interaction is not essential for its suppressor function. We also found that the direct in vivo interactions of the $2 \mathrm{~b}$ protein with AGO proteins require the functional nucleolar localization signal (NoLS) and redistribute the $2 \mathrm{~b}$ protein in the nucleus (Duan et al., 2012).

The roles of RNAi-mediated viral immunity against CMV were mostly illustrated using the mutant of CMV that does not express the $2 \mathrm{~b}$ protein or mutate by amino acid substitution in the N-terminal dsRNA binding domain of the 2b (DiazPendon et al., 2007; Wang et al., 2010; Xu et al., 2013; Dong et al., 2016). These mutants of CMV reduce virulence and virus accumulation in wild-type Arabidopsis plants, but are efficiently rescued in mutant plants defective in RNAi components, such as RDR1, RDR6, or DCL4, which shows that the $2 \mathrm{~b}$ protein plays critical roles in anti-RNAi defense and that its N-terminal dsRNA binding domain is required for the induction of virulence and virus accumulation in the CMV-infected plants (Diaz-Pendon et al., 2007; Wang et al., 2010; Xu et al., 2013; Dong et al., 2016). We previously found that the $2 \mathrm{~b}$-AGO interaction was not essential for the $2 \mathrm{~b}$ in suppression of silencing, however, we wondered what is the biological significance of the 2b-AGO interaction in the context of virus infection. To this end, we created mutants of CMV from the SD strain that expressed the $2 \mathrm{~b}$ functional domains of dsRNA- or AGO- binding activity (Duan et al., 2012) and tested the effect of these CMV mutants on viral pathogenicity. We found that the dsRNA-binding activity of the $2 \mathrm{~b}$ was essential for virulence, whereas the $2 \mathrm{~b}$-AGO interaction was necessary for interference with RDR1/6-dependent antiviral silencing in Arabidopsis. The possible benefit of the 2b-AGO interaction in CMV infectivity is discussed.

\section{MATERIALS AND METHODS Plant Material and Growth Conditions}

$N$. benthamiana plants were grown in a greenhouse at $25^{\circ} \mathrm{C}$ with 16-h light/8-h dark cycles. $r d r 1 / 6$ and wild-type Arabidopsis plants were grown in a greenhouse at $22^{\circ} \mathrm{C}$ with 16 -h light $/ 8$-h dark cycles.

\section{Plasmid Constructs}

35S-R1, 35S-R2, 35S-R3, and 35S-R $\Delta 2 \mathrm{~b}(\mathrm{R} 2 \mathrm{a} \Delta 2 \mathrm{~b})$ were described in a previous study (Hou et al., 2011). For R2a $2 b_{(1-76)}$, $\mathrm{R} 2 \mathrm{a} 2 \mathrm{~b}_{(8-111)}$, and $\mathrm{R} 2 \mathrm{a} 2 \mathrm{~b}_{(18-111)}$ point mutant constructs, mutagenesis was introduced using QuikChange ${ }^{\circledR}$ Lightning Site-Directed Mutagenesis Kits (Agilent Technologies, 210518) according to the manufacturer's instructions. The templates were $35 \mathrm{~S}-\mathrm{R} 2$, 35S-R2, and $\mathrm{R} 2 \mathrm{a} 2 \mathrm{~b}_{(8-111)}$, and the primer pairs were R2-2b77TGAF/R, R2-2b8-111F/R, and R2-2b18-111F/R, respectively (Table S1).

For the constructs used in dsRNA binding activities, pGEX$4 \mathrm{~T}-2-\mathrm{SD} 2 \mathrm{~b}$ was described in a previous study (Duan et al., 2012). The constructs pGEX-4T-2-SD2b $\mathrm{b}_{(8-111)}$ and pGEX-4T-2$\mathrm{SD}_{2} \mathrm{~b}_{(18-111)}$ were generated with the pGEX-4T-2-SD2b template using QuikChange ${ }^{\circledR}$ Lightning Site-Directed Mutagenesis Kits (Agilent Technologies, 210518) according to the manufacturer's instructions. The primer pairs were GST2b8-111F/R and GST2b18-111F/R for the constructs pGEX-4T-2-SD2b $\mathrm{b}_{(8-111)}$ and pGEX-4T-2-SD2b $\mathrm{b}_{(18-111)}$, respectively (Table $\mathrm{S} 1$ ).

For the constructs used in suppression activity, pBI121-35SSD2b was described in a previous study (Duan et al., 2012). To generate $\mathrm{pBI} 121-35 \mathrm{~S}-\mathrm{SD} 2 \mathrm{~b}_{(8-111)}$, $\mathrm{pBI} 121-35 \mathrm{~S}-\mathrm{SD} 2 \mathrm{~b}_{(18-111)}$, and pBI121-35S-SD2b $\mathrm{b}_{(1-76)}$, the $2 \mathrm{~b} 8-111 \mathrm{~F} / 2 \mathrm{bR}, 2 \mathrm{~b} 18-111 \mathrm{~F} / 2 \mathrm{bR}$, and $2 \mathrm{~b} 1-76 \mathrm{~F} / \mathrm{R}$ primers (Table S1) were used to amplify the $2 \mathrm{~b}_{(8-111)} / 2 \mathrm{~b}_{(18-111)} / 2 \mathrm{~b}_{(1-76)}$ mutant fragments with the template 
of pBI121-35S-SD2b; the resulting fragments were cut by $\mathrm{XbaI}-\mathrm{SacI}$ and inserted into the XbaI-SacI digested pBI121$35 S-S D 2 b$ vector to yield pBI121-35S-SD2b ${ }_{(8-111)}$, pBI121-35S$\mathrm{SD}_{2} \mathrm{~b}_{(18-111)}$, and pBI121-35S-SD2b $\mathrm{b}_{(1-76)}$.

For constructs used in the subcellular localization and SD2b-AGO colocalization, pBI121-35S-SD2b-EGFP and RFPAGO4 were described in a previous study (Duan et al., 2012). The constructs pBI121-35S-SD2b (8-111) $_{1}$ and pBI121-35S$\mathrm{SD}_{2} \mathrm{~b}_{(18-111)}$-EGFP were generated with the pBI121-35S-SD2bEGFP template using QuikChange ${ }^{\circledR}$ Lightning Site-Directed Mutagenesis Kits (Agilent Technologies, 210518) according to the manufacturer's instructions. The primer pairs were 2B8-111EGFPF/R and 2B18-111-EGFPF/R for the pBI121-35S-SD2bEGFP and RFP-AGO4 constructs, respectively (Table S1).

\section{Agrobacterium tumefaciens-Mediated Transient Expression and Virus Inoculation}

35S-R1, 35S-R3 and different R2 mutant constructs were coinfiltrated into the leaves of 5-week-old $N$. benthamiana plants, as described in a previous study (Hou et al., 2011). Systemically infected leaves were harvested from pools of 15 to 20 plants for sap extraction for viral infection. Similar levels of viral RNAs in each sap sample estimated by RNA gel blotting were inoculated to $N$. benthamiana and $A$. thaliana seedlings.

\section{RNA Extraction and RNA Gel Blot Analysis}

Plant total RNA used for RNA gel blotting was extracted by the hot-phenol method as previously described (Fernández et al., 1997). For the detection of viral RNAs, three $1-\mathrm{kb}$ fragments at the 3 '-terminus of each cDNA clone (35S-R1, 35S-R2, and 35SR3) were amplified, which were then labeled with $\left[\mathrm{a}^{32} \mathrm{P}\right] \mathrm{dCTP}$ using the Rediprime II system (GE Healthcare, RPN1633) and were mixed as probes. For the detection of siRNAs, $30 \mathrm{mg}$ of total RNA was separated on $17 \%$ polyacrylamide- $8 \mathrm{M}$ urea gels. The probes were labeled with $\left[\mathrm{r}^{32} \mathrm{P}\right] \mathrm{ATP}$ using T4 PNK (NEB, M0201V). VsiRNAs were detected using mixtures of labeled DNA oligonucleotides specific to RNA3. Signal intensity was quantified using ImageQuant TL software (GE Healthcare).

\section{Expression and Purification of Recombinant Proteins}

For the expression of fusion proteins in Escherichia coli, recombinant plasmids were transformed into BL21 cells and induced at $0.3 \mathrm{mM}$ isopropyl b-D-1thiogalactopyranoside (Sigma-Aldrich) in Luria-Bertani medium at $28^{\circ} \mathrm{C}$ for 3 to 6 h. GST-tagged fusion proteins were purified using Glutathione Sepharose 4B (GE Healthcare, 17-0756-01) according to the manufacturer's instructions.

\section{EMSAs}

21/24-bp ds-siRNA and 55-bp ds-RNA, which were described in a previous study (Duan et al., 2012), were radiolabeled in 50pmol quantities with $0.3 \mathrm{mM}\left[\mathrm{r}^{32} \mathrm{P}\right] \mathrm{ATP}$ and 20 units of T4 PNK (NEB, M0201V). Binding reactions were performed with 1 ng of radiolabeled ds-siRNA and $1 \mathrm{nmol}$ of protein in binding buffer (20 mM Tris- $\mathrm{HCl}, \mathrm{pH}$ 7.5, $5 \mathrm{mM} \mathrm{MgCl}$, $300 \mathrm{mM} \mathrm{NaCl}$, $0.1 \%$ Nonidet P-40, and protease inhibitor cocktail. After 40 min at room temperature, $1 \mathrm{~mL}$ of $50 \%$ glycerol and dye was added, and protein RNA complexes were resolved on $6 \%$ native polyacrylamide gel. The gels were then exposed to a storage phosphor screen (GE Healthcare).

\section{Subcellular Localization Assays}

The subcellular localization of $2 \mathrm{~b}$ mutants and their colocalization with AGO proteins were determined by infiltrating binary plasmids of pBI121-35S-SD2b-EGFP mutants and RFPAGO4 into 5-week-old $N$. benthamiana leaves, which were maintained for 3 days at $25^{\circ} \mathrm{C}(16$-h light/8-h dark). The nuclei were stained with $100 \mathrm{ng} / \mathrm{mL} \mathrm{4}$,6-diamidino-2-phenylindole (DAPI) for $10 \mathrm{~min}$ before confocal microscopy. Confocal fluorescence of GFP, RFP, and DAPI were captured with a Leica SP8 confocal microscope.

\section{RESULTS}

\section{Construction of the Infectious Clones of SD-CMV with Different Mutations in the $2 b$ Coding Sequence}

We previously constructed infectious clones of SD-CMV with the viral genomic RNA1, RNA2, and RNA3 under the 35S promoter (Figure 1A) and a chimeric RNA2 $(\Delta 2 \mathrm{~b})$ infectious clone, in which $2 \mathrm{~b}$ protein expression was abolished by nucleotide substitution in the start codon ATG, as well as four other ATG codons in the $2 \mathrm{~b}$ coding sequence, but $2 \mathrm{a}$ protein expression was unaffected, designated as CMV $\Delta 2 \mathrm{~b}$ (Figure 1A; Hou et al., 2011). To investigate the biological functions of the different biochemical properties of the $2 \mathrm{~b}$ protein in the context of CMV infection in plants, in this study, we further created mutations of $2 \mathrm{~b}$ of the genomic RNA2 according to the two main biochemical properties of double-stranded RNA (dsRNA) and AGO binding activities (Duan et al., 2012). As shown in Figure $1 \mathrm{~A}$, in addition to the above $\Delta 2 \mathrm{~b}$, three $2 \mathrm{~b}$ mutants were created by deleting the C-terminal 35 amino acids (aa) and creating a stop codon in the $2 \mathrm{~b}$ coding sequence to yield $2 b_{(1-76)}$ without affecting the overlapping portion of the $2 a$ polymerase. Another two mutants were created by deleting the $\mathrm{N}$-terminal 7 or 17 aa to yield $2 \mathrm{~b}_{(8-111)}$ and $2 \mathrm{~b}_{(18-111)}$ by nucleotide substitution in the 1 st or both the 1st and 8th "ATG" codons of the $2 \mathrm{~b}$ coding sequence without affecting the 2 a protein. To obtain viral sources of chimeric CMV with different $2 \mathrm{~b}$ mutant, each of these constructs was transformed into Agrobacterium for the infiltration of $N$. benthamiana in the presence of 35S-RNA1 and 35S-RNA3 to examine the infectious properties of the chimeric CMV with 35S-2bx ( $\mathrm{x}$ represents different $2 \mathrm{~b}$ mutations shown in Figure 1A), and the related viruses were referred to as wild-type CMV, CMV $\Delta 2 \mathrm{~b}$, $\mathrm{CMV}_{2} \mathrm{~b}_{(1-76)}, \mathrm{CMV}_{(8-111)}$, and $\mathrm{CMV}_{(18-111)}$ (Figure 1B and Supplementary Figure S1).

Typical symptoms were observed in CMV-, CMV2 $\mathrm{b}_{(1-76)^{-}}$, and $\mathrm{CMV}_{2} \mathrm{~b}_{(8-111)}$-inoculated plants, whereas CMV $\Delta 2 \mathrm{~b}$ and $\mathrm{CMV}_{(18-111)}$-inoculated plants did not develop visible symptoms (Supplementary Figure S1). However, as shown in Figure 1B, RNA gel blot analysis confirmed that the three CMV 


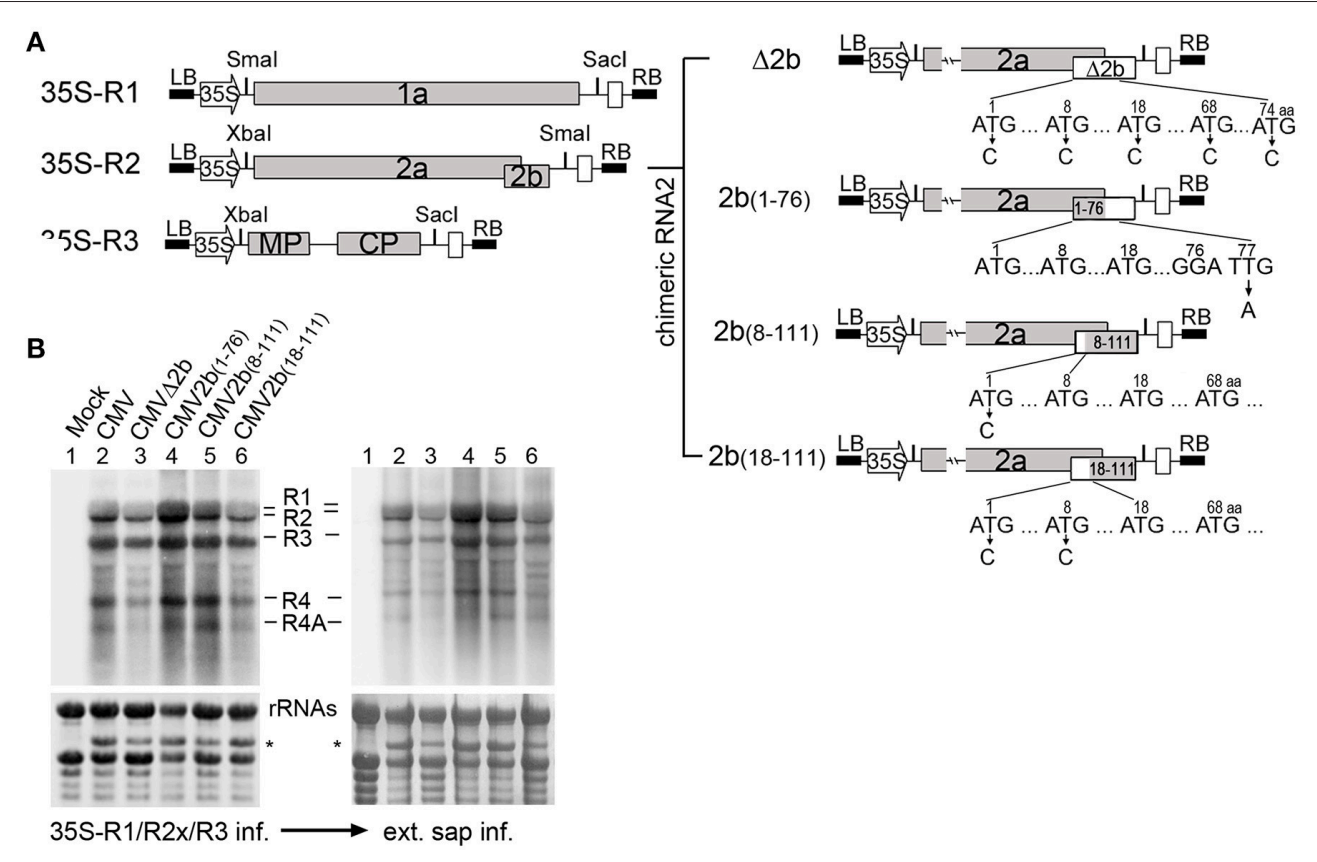

FIGURE 1 | Construction and biological activities of $\mathbf{2 b}$ mutants in the context of $\mathbf{C M V}$ infection. (A) Diagram of SD-CMV infectious clone construction. 35S-R1, 35S-R2, and 35S-R3 were the three full-length clones of SD-CMV genomic RNA1, RNA2, and RNA3 as well as four chimeric RNA2 mutants. R2a $\triangle 2 \mathrm{~b}, 2 \mathrm{~b}$ protein expression was abolished; R2a2 $\mathrm{b}_{(1-76)}$, with deletion of the C-terminal 35 amino acids; R2a2b $\mathrm{b}_{(8-111)}$, with deletion of the $\mathrm{N}$-terminal seven amino acids; and R2a2b $(18-111)$, with deletion of the N-terminal 17 amino acids. Substituting "C" for each "T" in the start codon ATG, as well as other ATG codons, or "A" for "T" in creating stop codon present in the $2 \mathrm{~b}$ coding sequence are indicated with the numbers of the amino acid positions. (B) RNA gel blot detection of CMV accumulation in Agrobacterium-inoculated leaves (left panel) and the plants inoculated with sap extracted from each CMV2b(x) -infected Nb leaf (right panel). SD-CMV genomic RNA $3^{\prime}$ UTR was used as a probe. Methylene blue-stained ribosomal rRNA was used as loading control. *A stained viral RNA used as an indicator of SD-CMV infection.

genomic RNA1, RNA2, and RNA3 transcripts, as well as both subgenomic RNA4 and 4A transcripts, were accumulated in noninoculated systemic leaves for all chimeric viruses detected using the $3^{\prime}$-untranslated region $\left(3^{\prime}\right.$-UTR) as a probe (Figure $1 B$ ). This indicated that the infiltration of the mixture could sustain the replication of both subgenomic RNA4 and 4A. RT-PCR and sequencing analysis of viral RNAs isolated from infected plants confirmed that all chimeric 2 bx mutations were genetically stable in $N$. benthamiana $(\mathrm{Nb})$ plants. Similar symptom development and the accumulation of viral RNAs were obtained in the $\mathrm{Nb}$ plants inoculated with sap extracted from these each chimeric $\mathrm{CMV}$-infected $\mathrm{Nb}$ leaves (Figure 1B).

\section{Detection of the dsRNA and AGO Binding Activities of the Deletion Mutants of the $2 b$ Protein}

We previously uncoupled the $2 \mathrm{~b}$ domain requirements for dsRNA binding and nucleolar targeting from the physical interaction with AGO proteins (Duan et al., 2012). The 61 aa $\mathrm{N}$-terminal end $\left[2 \mathrm{~b}_{(1-61)}\right]$, which contains the complete $\alpha 1$ linker- $\alpha 2$ structure involved in dsRNA binding, retained the wild-type $2 \mathrm{~b}$ ability to bind 21- and 24-nt siRNA duplexes, whereas $2 b_{(13-111)}$ exhibited weak affinity for 21-nt siRNA but showed no detectable affinity for 24-nt siRNA (Duan et al., 2012). To characterize the dsRNA binding activities of $2 \mathrm{~b}_{(8-111)}$ and $2 \mathrm{~b}_{(18-111)}$, which corresponded to the deletion mutants constructed in the context of the CMV RNA2 genome
(Figure 1A), we performed electrophoretic mobility shift assays (EMSAs) with the full-length of $2 \mathrm{~b}, 2 \mathrm{~b}_{(8-111)}$, and $2 \mathrm{~b}_{(18-111)}$ expressed and purified as GST fusion proteins (Figures 2A,B). Similar to previous results (Duan et al., 2012), 2b exhibited high affinity for either small 21- and 24-nt siRNA duplexes or long dsRNA (Figure 2B). $2 \mathrm{~b}_{(8-111)}$ was almost as active as $2 \mathrm{~b}$ in binding to the 21- and 24-nt siRNA duplex but exhibited reduced affinity for long dsRNA (Figure 2B). Deletion of 17 aa from the $\mathrm{N}$ terminus abolished both of the siRNA dsRNA binding activities (Figure 2B), which indicated that further deletion of 4 aa (from 13 to $17 \mathrm{aa}$ ) in the $\mathrm{N}$-terminal $\alpha 1$ helix completely abolished the weak affinity for $21-n t$ siRNA of $2 b_{(13-111)}$. Consistently, $2 \mathrm{~b}_{(13-111)}$ retained the partial silencing suppression activity detected using an Agrobacterium coinfiltration assay (Duan et al., 2012); however, $2 b_{(18-111)}$ failed to suppress GFP silencing as indicated by the lack of green fluorescence in the co-infiltrated leaves, in which $2 \mathrm{~b}_{(8-111)}$ was almost as active as $2 \mathrm{~b}$ in the suppression of GFP silencing (Figure 2C).

We next investigated the subcellular localization of $2 \mathrm{~b}_{(8-111)}$ and $2 \mathrm{~b}_{(18-111)}$ and their possible interaction with the AGO protein in $N$. benthamiana leaf epidermal cells. $2 \mathrm{~b}_{(8-111)}$ and $2 b_{(18-111)}$ fused at their C-termini with enhanced green fluorescent protein (EGFP) were transiently expressed in $N$. benthamiana via Agrobacterium-mediated infiltration. The 2b-EGFP (Duan et al., 2012) was used as a control. Similar to $2 \mathrm{~b}$-EGFP, both $2 \mathrm{~b}_{(8-111)}$-EGFP, and $2 \mathrm{~b}_{(18-111)}$-EGFP were mainly detected in the nucleus with dense fluorescence in the 


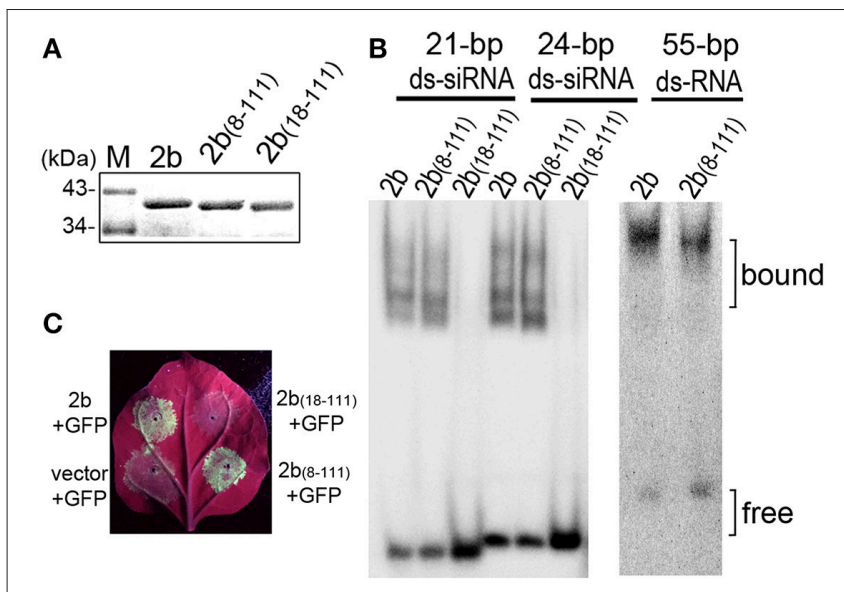

FIGURE 2 | Detection of the suppression of the transgene-induced silencing and dsRNA-binding activity of $\mathbf{2 b}$ and its mutations. (A) Purified GST-tagged 2b, 2b(8-111), and 2b $b_{(18-111)}$. (B) Gel mobility shift assays for the detection of the dsRNA binding affinity. GST-tagged 2b, $2 \mathrm{~b}_{(8-111)}$, and $2 \mathrm{~b}_{(18-111)}$ were incubated with siRNA duplexes and long dsRNA. $2 b_{(8-111)}$ showed a high affinity for 21/24-nt siRNA duplexes, similar to $2 b$, but showed a reduced affinity for long dsRNA; $2 b_{(18-111)}$ showed no binding to 21/24-nt siRNA duplexes. (C) GFP fluorescence in the leaves of Nb plants coinfiltrated with GFP and 2b or mutants. Coinfiltration of GFP with vector was used as control. Photographs were taken under UV light at 4 dpi.

nucleoli (Figure 3A), consistent with both deletion mutants containing NoLS from the 13 to 37 region, including both NLSs (Figure 3C). This allowed for the accumulation of the fusion protein in the nucleoli and nucleus (Duan et al., 2012).

Coexpression of 2b-EGFP and RFP-AGO4 resulted in their colocalization in the nucleus with dense fluorescence in nucleusassociated bodies (Figure 3B), which was consistent with our previous finding that the redistribution of $2 \mathrm{~b}$-EGFP in the nucleus when coexpressed with AGO proteins (Duan et al., 2012). Similar nuclear colocalization and redistribution was observed for $2 \mathrm{~b}_{(8-111)}$-EGFP, but not $2 \mathrm{~b}_{(18-111)}$, when they were coexpressed with RFP-AGO4 (Figure 3B). Intriguingly, the densities of fluorescence were greatly reduced for both $2 \mathrm{~b}_{(18-111)^{-}}$ EGFP and RFP-AGO4 when they were coexpressed compared to that of each when expressed alone (cf. Figures 3A,B). One of the possible explanations might be that the interaction of $2 b_{(18-111)}$-EGFP and RFP-AGO4 caused the instability of both proteins due to $2 \mathrm{~b}_{(18-111)}$ 's lack of binding to ds-siRNA and suppression of silencing (Figures 2B,C). Nevertheless, these data demonstrate that the deletion of 17 aa from the $\mathrm{N}$ terminus of the $2 \mathrm{~b}$ protein completely abolished both the long dsRNA and ds-siRNA binding activity, whereas the deletion of 7 aa from the $\mathrm{N}$ terminus retained the wild-type $2 \mathrm{~b}$ abilities in binding both dssiRNA and AGO protein but reduced the affinity for binding long dsRNA compared to wild-type $2 b$.

\section{Correlation of Virulence and Viral RNA Levels with Different $2 b$ Mutations in Wild-Type Arabidopsis Plants}

To investigate the biological functions of the different biochemical properties of the $2 \mathrm{~b}$ protein in the context of CMV infection in plants, wild-type Arabidopsis plants were inoculated with sap extracted from the above $N$. benthamiana leaves infected with CMV, CMV $\Delta 2 \mathrm{~b}, \mathrm{CMV}_{2} \mathrm{~b}_{(1-76)}, \mathrm{CMV}_{2} \mathrm{~b}_{(8-111)}$, or $\mathrm{CMV} 2 \mathrm{~b}_{(18-111)}$. The development of disease symptoms in Arabidopsis plants was monitored. At 9 days post-inoculation (dpi), plants infected with wild-type CMV displayed severe developmental defects, including reduced leaf size and a shortened petiole, and all new leaves were aggregatecd in the center of the plants as observed at $21 \mathrm{dpi}$ (Figure 4A). Plants inoculated with CMV $\Delta 2 \mathrm{~b}$ displayed no symptoms and normal growth compared to mock infection plants. $\mathrm{CMV}_{2} \mathrm{~b}_{(1-76)^{-}}$ infected plants displayed severe developmental defects similar to CMV-infected plants, and the development of both CMVand $C M V 2 b_{(1-76)}$-infected plants was arrested with short and defective inflorescence at $21 \mathrm{dpi}$ (Figure 4A). CMV2 $\mathrm{b}_{(8-111)^{-}}$ infected plants also showed typical defects in development and inflorescence, albeit less stunting. However, CMV2 $\mathrm{b}_{(18-111)^{-}}$ infected plants exhibited very mild symptoms, and plant growth was not arrested (Figure 4A). RT-PCR and sequencing analysis of viral RNAs isolated from infected plants confirmed that all chimeric $2 \mathrm{bx}$ mutations are genetically stable in Arabidopsis.

RNA gel blot analysis confirmed that three CMV genomic (RNA1, RNA2, and RNA3) and both subgenomic (RNA4 and 4A) transcripts were accumulated in the systeimic leaves of these infected plants (Figure 4B). Consistent with the degree of disease, minimal and small quantities of viral RNAs in CMV $\Delta 2 \mathrm{~b}$ - and $\mathrm{CMV}_{2} \mathrm{~b}_{(18-111)}$-infected plants were detected (Figure 4B). Intriguingly, similar severities of disease symptoms were observed for CMV-, CMV2 $\mathrm{b}_{(1-76)^{-}}$, and $\mathrm{CMV}_{2} \mathrm{~b}_{(8-111)^{-}}$ infected plants; however, the level of viral RNAs in $\mathrm{CMV}_{2} \mathrm{~b}_{(1-76)^{-}}$ infected plants was obviously lower than that in CMV- and $\mathrm{CMV}_{2} \mathrm{~b}_{(8-111)}$-infected plants (Figure 4B). $2 \mathrm{~b}_{(1-76)}$ lacked the AGO binding domain but retained the dsRNA-binding domain and the silencing suppression activity (Figure 4C). Therefore, we examined the production of viral siRNAs (vsiRNAs) in these infected plants. High levels of vsiRNAs were detected in CMV2 $\mathrm{b}_{(1-76)}$-infected plants compared to wild-type and those infected with other chimeric viruses (Figure 4B), which was consistent with the low level of viral RNAs in these plants. No major differences in the accumulation of miR173 were detected following infection with either wild-type or each mutant CMV, which supported an earlier observation that CMV infection does not alter miRNA accumulation (Diaz-Pendon et al., 2007). These results demonstrate that $\mathrm{N}$ terminal dsRNA binding activity is responsible for the induction of the virulence of CMV, which does not necessarily correlate with the accumulation of viral RNAs, and $2 \mathrm{~b}-\mathrm{AGO}$ binding is likely required for CMV to suppress the silencing of viral RNAs in Arabidopsis plants.

\section{Correlation of Virulence and Viral RNA Levels with Different 2b Mutations in RDR1/RDR6-Deficient Mutants}

Previous studies showed that the $2 \mathrm{~b}$ gene of the CMV Fny strain is required for interference with RDR1- and RDR6dependent antiviral silencing (Diaz-Pendon et al., 2007; Dong 
A
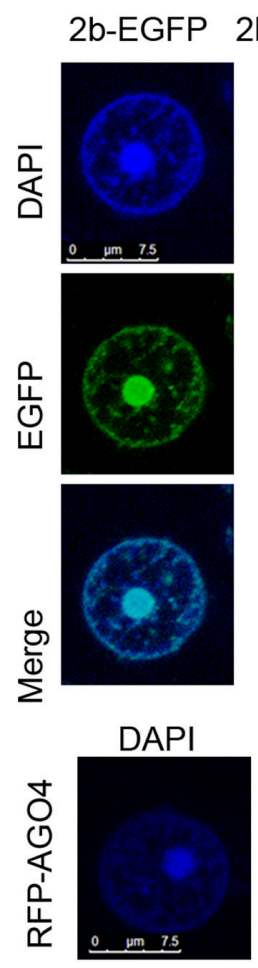

$2 \mathrm{~b}(8-111)-E G F P$
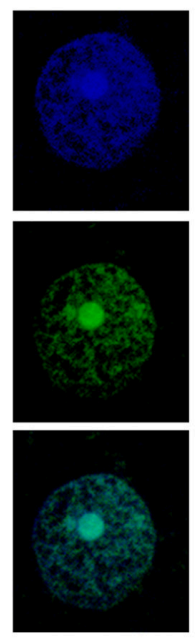

RFP

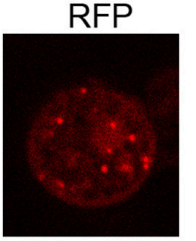

$2 b(18-111)-E G F P$
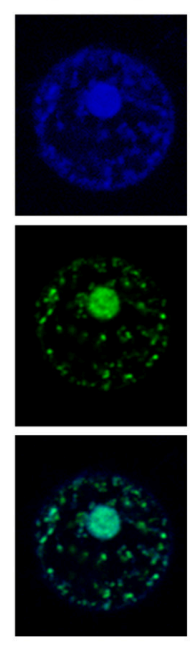

Merge

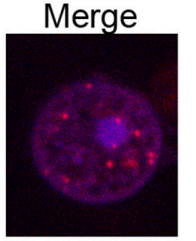

B
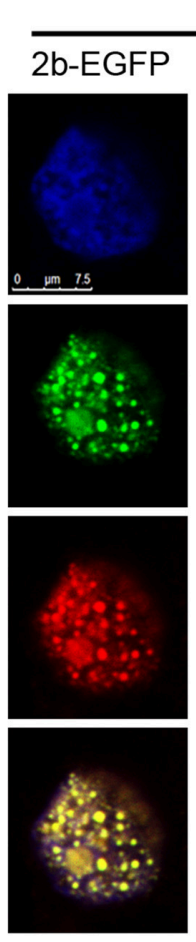

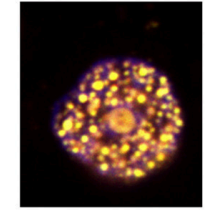

RFP-AGO4 +
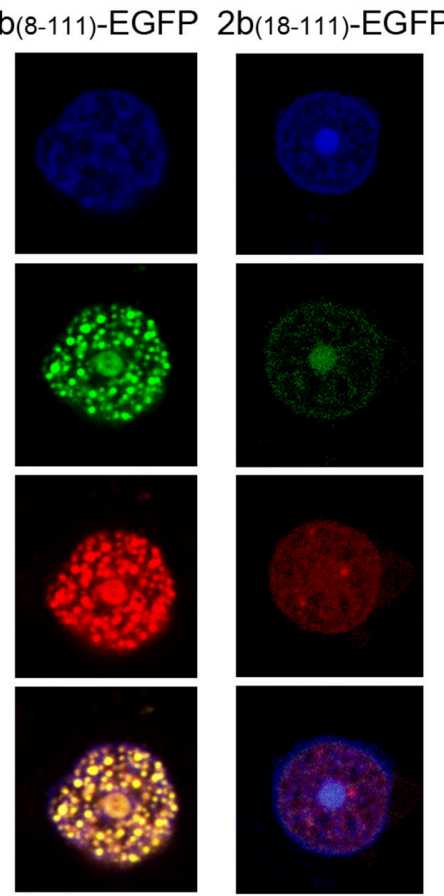

C

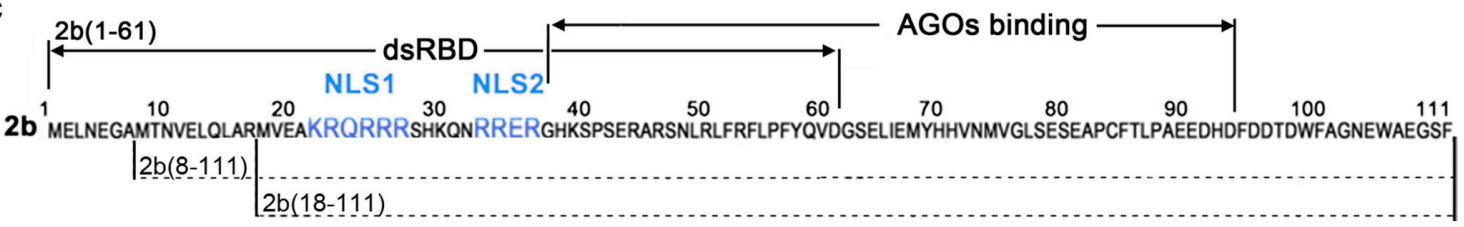

FIGURE 3 | Colocalization pattern of $\mathbf{2 b}$ or its derivative mutants with AGO4 in $\mathbf{N b}$ leaf epidermal cells. (A) Subcellular localization of $2 b-E G F P$, $2 b_{(8-111)}$-EGFP, 2b $b_{(18-111)}$-EGFP, and RFP-AGO4 in Nb leaf epidermal cells. DAPI staining was performed to represent the nuclei. Bars $=7.5 \mu \mathrm{m}$. (B) Subcellular location of the coexpression of 2b-EGFP, 2b $b_{(8-111)}$-EGFP, or 2 $\mathrm{b}_{(18-111)}$-EGFP with RFP-AGO4. (C) Diagram of the 2b function domain as previously reported (Duan et al., 2012). NLS, nuclear localization signal.

et al., 2016). To examine whether the accumulation of CMVderived vsiRNAs in $\mathrm{CMV}_{2} \mathrm{~b}_{(1-76)}$-infected plants was dependent on RDR proteins, we inoculated Arabidopsis with double mutants of RDRs (RDR1 and RDR6) with wild-type CMV, CMV $\Delta 2 \mathrm{~b}$, $\mathrm{CMV}_{2} \mathrm{~b}_{(1-76)}$, CMV2b $\mathrm{b}_{(8-111)}$, or CMV2 $\mathrm{b}_{(18-111)}$. Trans-acting siRNA tasiR255 was absent in the tested $r d r 1 / 6$ plants, verifying that the $R D R$ mutant alleles (Figure 5B). CMV $\triangle 2 \mathrm{~b}$ remained defective in inducing virulence in $r d r 1 / 6$ mutant; CMV $\Delta 2 \mathrm{~b}$ infected plants displayed no symptoms and normal growth compared to mock infection plants (Figure 5A). Similar to infected wild-type Arabidopsis plants, $r d r 1 / 6$ plants infected with CMV-, CMV2 $\mathrm{b}_{(1-76)^{-}}$, and CMV2 $\mathrm{b}_{(8-111)}$ displayed severe developmental defects, and whole plant development was arrested, although less stunting was observed in $\mathrm{CMV}_{2} \mathrm{~b}_{(8-111)^{-}}$ infected $r d r 1 / 6$ plants (Figure 5A). CMV2b $\mathrm{b}_{(18-111)}$-infected $r d r 1 / 6$ mutant plants exhibited mild but clear disease symptoms (Figure 5A). The inflorescences of $\mathrm{CMV}_{(18-111)}$-infected rdr1/6 plants were shorter and defective compared to those of CMV2 $\mathrm{b}_{(18-111)}$-infected wild-type plants (Figure 4A), which demonstrated that $2 \mathrm{~b}_{(18-111)}$ retained partial activity in the suppression of RDR6- and/or RDR1-mediated antiviral defense.

We further conducted RNA gel blot hybridizations to compare the accumulation of viral RNAs in these infected $r d r 1 / 6$ mutant plants. Consistent with the asymptomatic phenotype, minimal levels of viral RNAs in CMV $\Delta 2$ b-infected plants were detected (Figure 5B). Interestingly, a similar severity of disease symptoms was observed for CMV-, $\mathrm{CMV}_{2} \mathrm{~b}_{(1-76)^{-}}$, and $\mathrm{CMV}_{2} \mathrm{~b}_{(8-111)^{-}}$ infected $r d r 1 / 6$ plants; however, the accumulation level of viral RNAs in CMV2 $\mathrm{b}_{(1-76)}$-infected plants was clearly higher than that in CMV- and $\mathrm{CMV}_{2} \mathrm{~b}_{(8-111)}$-infected mutant plants (Figure 5B), opposite of that detected in infected wild-type Arabidopsis plants, in which a lower level of viral RNAs accumulated in CMV2 $\mathrm{b}_{(1-76)}$-infected plants than in CMV- and $\mathrm{CMV}_{2} \mathrm{~b}_{(8-111)}$-infected plants (Figure 4B). 
A
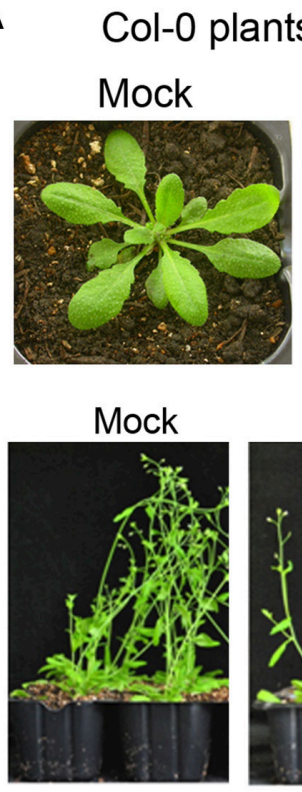

CMV2b(1-76)

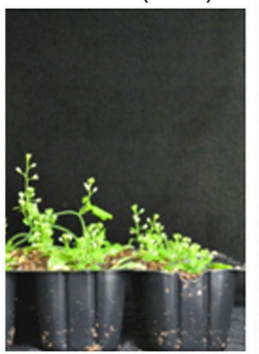

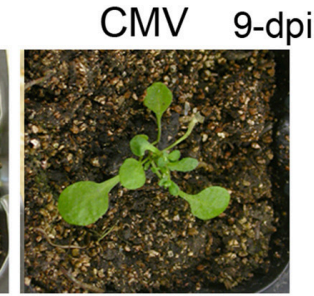

CMV

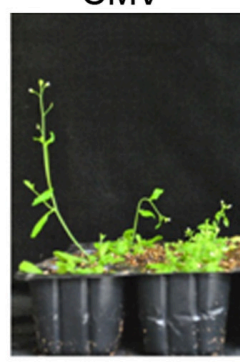

CMV2b(8-111)

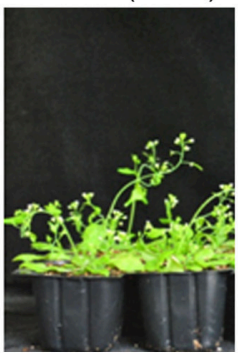

B

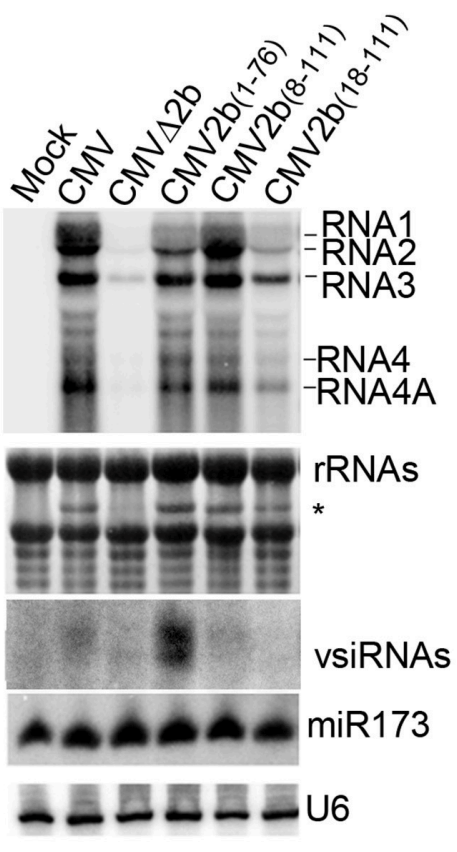

C

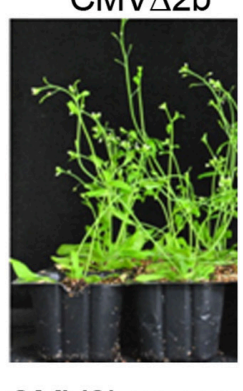

CMV2b(18-111)

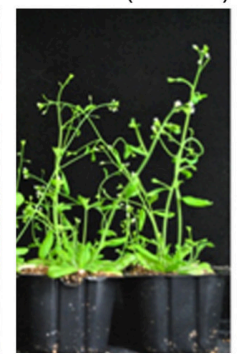

\section{$2 b+$ GFP}

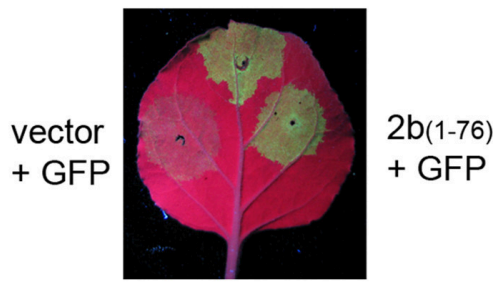

FIGURE 4 | Effects of $\mathbf{2 b}$ and its mutants on the virulence and accumulation of viral RNAs in infection with wild-type Arabidopsis plants. (A) Disease symptoms in wild-type Arabidopsis plants inoculated with CMV and CMV2b $(x)$ at 9 dpi and 21 dpi. (B) RNA gel blot detection of viral genomic RNAs and vsiRNAs. Methylene blue-stained ribosome rRNA and U6 were used as the loading control. (C) GFP fluorescence in the leaves of $\mathrm{Nb}$ plants coinfiltrated with GFP and $2 \mathrm{~b}$ or mutants. Coinfiltration of GFP with vector was used as control.

We then examined the production of vsiRNAs. Remarkably, vsiRNAs in CMV2b $\mathrm{b}_{(1-76)}$-infected $r d r 1 / 6$ plants (Figure 5B) were greatly reduced compared to $\mathrm{CMV} 2 \mathrm{~b}_{(1-76)}$-infected wildtype Col-0 plants (Figure 4B). These results indicated that RDR6 and/or RDR1 play role(s) in partially silencing CMV RNAs disrupted by $2 \mathrm{~b}$-AGO binding activity. Taking into account of the low level of viral RNAs and the high level of vsiRNAs in CMV2 $\mathrm{b}_{(1-76)}$ infected wild-type plants, our data demonstrate that the $2 \mathrm{~b}$-dsRNA binding activity is insufficient to suppress the host degradation of viral RNA that requires the functions of RDR6 and/or RDR1.

\section{DISCUSSION}

In our previous study, we characterized the SD-CMV $2 \mathrm{~b}$ protein in terms of subcellular localization, RNA binding, AGO interaction, and the suppression of RNA silencing (Duan et al., 2012). We found that dsRNA sequestration is the predominant mechanism by which $2 \mathrm{~b}$ suppresses silencing and that the $2 \mathrm{~b}$ AGO interaction is not essential for its suppressor function. In this study, we further explored the biological significance of different functional activities of the $2 \mathrm{~b}$ protein in the context of virus infection. By creating mutants of SD-CMV that expressed different $2 b$ functional domains, either retaining the dsRNAbinding activity or the AGO-binding activity, we found that 2b's dsRNA-binding activity was essential for virulence and viral RNA propagation, whereas the $2 \mathrm{~b}-\mathrm{AGO}$ interaction was necessary for interference with RDR-dependent antiviral silencing in Arabidopsis.

The $2 \mathrm{~b}_{(8-111)}$ mutant protein with 7 aa deleted from the $\mathrm{N}$ terminus was almost as active as wild-type $2 \mathrm{~b}$ in binding to 21 and 24-nt ds-siRNA duplex and in the suppression of transgene GFP silencing (Figure 2). Therefore, $\mathrm{CMV}_{2} \mathrm{~b}_{(8-111)}$ caused wildtype CMV-like to impact both the viral RNA level and the virulence in either wild-type Arabidopsis or $r d r 1 / 6$ mutant plants. However, we also noted that the stunted phenotype was less severe in $\mathrm{CMV} 2 \mathrm{~b}_{(8-111)}$-infected plants. This might be related 


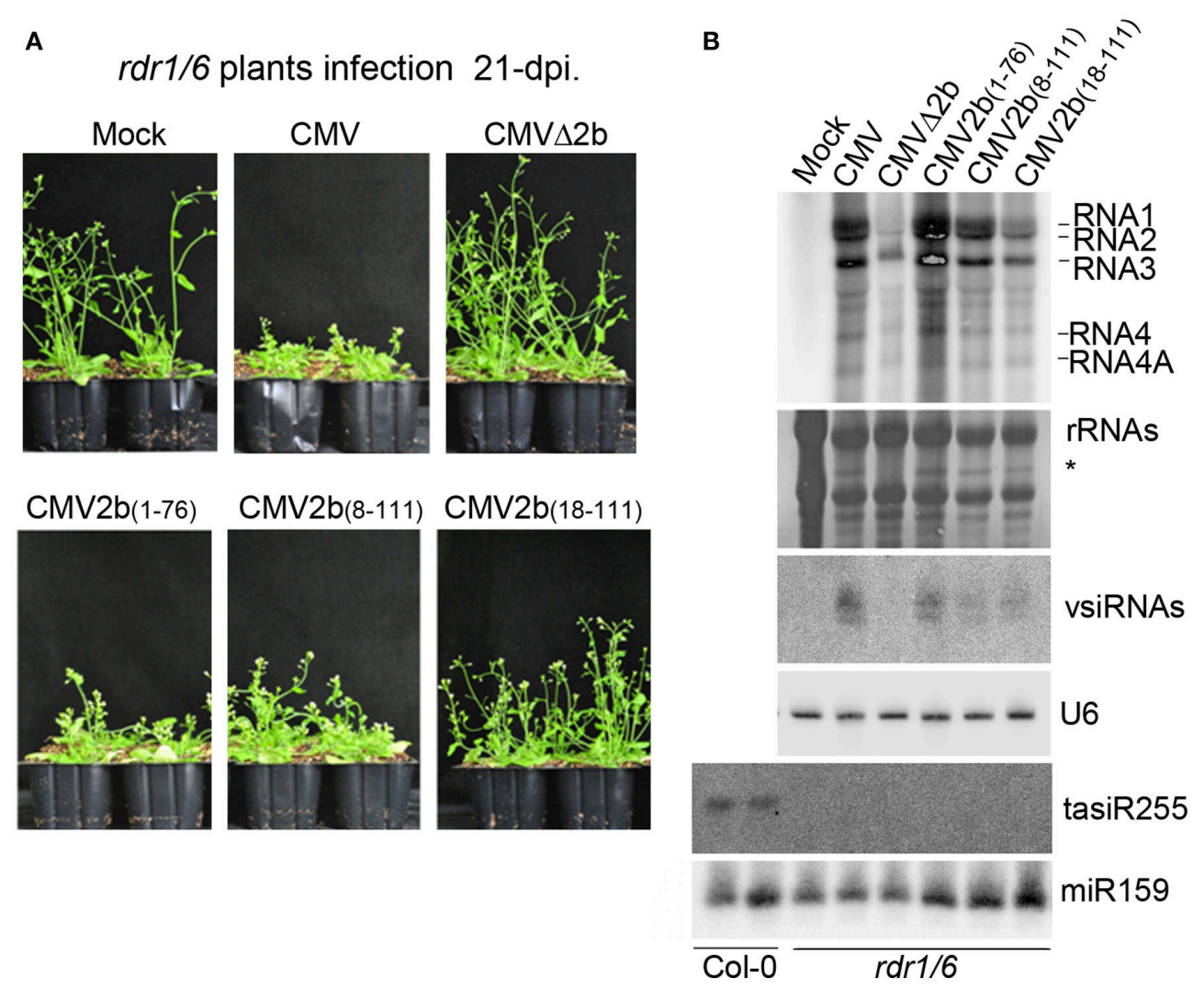

FIGURE 5 | Effects of $\mathbf{2 b}$ and its mutants on the virulence and accumulation of viral RNAs in infection of rdr1/6 plants. (A) Disease symptoms in rdr1/6 plants inoculated with CMV and CMV2b $\mathrm{b}_{(x)}$ at $21 \mathrm{dpi}$. (B) RNA gel blot detection of viral genomic RNAs and vsiRNAs. tasiR255 was used to verify the RDR mutant alleles. Methylene blue-stained ribosome rRNA and U6 as well as miR159 were used as the loading controls.

to its reduced activity in binding long dsRNA compared to that of wild-type $2 \mathrm{~b}$ (Figure $2 \mathrm{~B}$ ). This observation suggests that the first 7 aa of the $2 b$ protein might affect the N-terminal $\alpha 1$ helix, which is followed by the short linker and the $\alpha 2$ helix structure involved in long dsRNA binding (Chen et al., 2008). Indeed, we previously found that $2 b_{(13-111)}$ with the deletion of the $\mathrm{N}$ terminal 12 aa was defective in binding long dsRNA and 24nt ds-siRNA but retained very weak 21-nt ds-siRNA binding ability, which revealed that the $\mathrm{N}$-terminal $\alpha 1$ helix is essential for binding to long dsRNA (Duan et al., 2012). Thus, even $2 \mathrm{~b}_{(8-111)}$ was as active as wild-type $2 \mathrm{~b}$ in binding both 21 - and 24 -nt dssiRNA, it was defective in binding long dsRNA. Thus, $2 \mathrm{~b}_{(8-111)}$ may be defective in binding, for example, endogenous long noncoding RNAs that have emerged as new regulatory elements with essential roles in plant development and stress signaling pathways (Wu et al., 2013; Zhu et al., 2014; Wang et al., 2015), which may explain the less stunted phenotype in $\mathrm{CMV} 2 \mathrm{~b}_{(8-111)}$-infected plants.

Deletion of 17 aa from the $2 \mathrm{~b} \mathrm{~N}$ terminus abolished both the siRNA-binding and silencing suppressor activities (Figure 2). CMV2 $\mathrm{b}_{(18-111)}$ infection never achieved the wild-type CMV level of viral RNAs in either wild-type Arabidopsis or $r d r 1 / 6$ mutant plants (Figures 4, 5). However, in comparison with $\mathrm{CMV} \Delta 2 \mathrm{~b}$ infection, the level of viral RNAs was clearly higher in
CMV2b $\mathrm{b}_{(18-111)}$-infected wild-type Arabidopsis, but not obvious in $r d r 1 / 6$ plants, which implied that the $2 \mathrm{~b}_{(18-111)}$ had a role in countering the RDR-dependent defense against CMV accumulation. We previously found that in vivo, the 2b-AGO interaction depends also on the nucleolar targeting of the $2 \mathrm{~b}$ protein (Duan et al., 2012). $2 b_{(18-111)}$ retained the AGO-binding domain, and its nucleolar targeting was evident (Figure 3A). However, taking into account that the instability of both the $2 \mathrm{~b}_{(18-111)}-\mathrm{EGFP}$ and RFP-AGO4 fusion proteins when they were co-expressed (Figure 3B), we speculated that it would decrease the effect of $2 b_{(18-111)}$ on countering RDR-dependent resistance in the absence of dsRNA binding activity. A previous study that examined the $2 \mathrm{~b}-\mathrm{AGO} 4$ interaction using the BiFC assay found that the fluorescent signal of the 2b-AGO4 interaction was reduced in $r d r 2$ mutant plants, which compromised the accumulation of 24-nt siRNAs (Hamera et al., 2012). Taken together, these findings suggest that a lack of siRNAs in the formation of the $2 \mathrm{~b}_{(18-111)}-\mathrm{AGO} 4$ complex might result in the degradation of both proteins.

The effect of the $2 \mathrm{~b}$-AGO interaction in counteracting RDRdependent antiviral silencing was substantiated by comparing the levels of viral RNAs and siRNAs in CMV2 $\mathrm{b}_{(1-76)}$-infected wild-type Arabidopsis and $r d r 1 / 6$ mutant plants (Figures 4, 5). Retaining the dsRNA-binding activity but lacking the 
AGO-binding domain, $2 \mathrm{~b}_{(1-76)}$ failed to suppress the RDRdependent degradation of viral RNAs, resulting in the production of a large quantity of vsiRNAs and a decrease in the viral RNA level (Figure 4B). This finding clearly demonstrated that the 2b-AGO binding activity is required for CMV to counter the host's RDR-dependent degradation of viral RNAs. The physical interaction of $2 \mathrm{~b}$ with AGOs requires the region encompassing residues 62 to 94 (Duan et al., 2012). Although this region is highly variable in sequence, it is present among all of the cucumoviral 2b proteins (Ding et al., 1994), which reveal its important in vivo function for CMV infection.

We found that the $2 \mathrm{~b}$ dsRNA binding activity is responsible for the induction of virulence, which did not necessarily correlate with the level of CMV RNAs (Figure 4). This is consistent with a previous finding that Fny-CMV2bNLS, an Fny strain expressing the $2 \mathrm{~b}$ mutant with an additional NLS and enhanced nuclear targeting, increased viral virulence but decreased virus accumulation and increased vsiRNAs (Du et al., 2014a). The authors therefore proposed that partitioning the $2 \mathrm{~b}$ protein between the cytoplasmic and nuclear/nucleolar compartments allows CMV to regulate the balance between virus accumulation and damage to the host ( $\mathrm{Du}$ et al., 2014a). We previously found that the $2 \mathrm{~b}-\mathrm{AGO}$ interaction redistributed both the $2 \mathrm{~b}$ and AGO proteins in the nucleus (Duan et al., 2012). The nucleus/nucleolus-localized 2bNLS failed to increase virus accumulation in Fny-CMV2bNLS infection, which might be attributed to the disrupted redistribution of $2 \mathrm{~b}-\mathrm{AGO}$. This likely resembled the $2 b_{(1-76)}$ failure in interactions with AGO proteins and the inhibition of viral RNA degradation in Fny-CMV2bNLS infection. It was also reported that Fny-CMV2blm expressing the $2 \mathrm{~b}$ mutant defective in ds-siRNA binding activity drastically attenuated the virulence in wild-type Arabidopsis plants (Dong et al., 2016). Virulence could be efficiently rescued in CMV2blminfected plants harboring RDR6-deficient mutations, including $r d r 6, r d r 1 / 6, r d r 2 / 6$, and $r d r 1 / 2 / 6$, but not $r d r 1$ and $r d r 2$ mutant plants. Viral RNAs also accumulated to higher levels in $r d r 6$ and $r d r 1 / 6$ than in wild-type Arabidopsis plants (Dong et al., 2016). Unlike the wild-type $\mathrm{N}$ terminus of $2 \mathrm{~b}$, which was required to form dimers, tetramers and oligomers, $2 \mathrm{blm}$ could only form dimers (Dong et al., 2016). Therefore, the rescued virulence and viral RNA level in CMV2blm-infected RDR6-deficient mutant plants was suggested due to the low oligomerization of the $2 \mathrm{blm}$ that directly weakened ds-siRNA binding activity (Dong et al., 2016). The 2blm contained the full-length sequence with double alanine substitution (L15A and M18A) mutations at the N-terminus but retained the long dsRNA binding domain (Dong et al., 2016). Thus, unlike 2b $\mathrm{b}_{(18-111)}$, which caused the instability of the interacting $2 \mathrm{~b}_{(18-111)}$-AGO proteins (Figure 3B), 2blm might bind to AGO but retain the stability of two proteins due to its long dsRNA binding activity. This may rescue the virulence in $r d r 6$ mutant plants, in which the RDR1-mediated degradation of viral RNAs might be suppressed by the $2 \mathrm{blm}-\mathrm{AGO}$ interaction. In our study, the N-terminal 17 aa deletion mutant $2 \mathrm{~b}_{(18-111)}$ contained the AGO-binding domain but was defective in binding long and short dsRNA. Neither severe disease symptoms nor high viral RNA level were obtained with $\mathrm{CMV} 2 \mathrm{~b}_{(18-111)}$ infection in $r d r 1 / 6$ plants (Figure 5), which demonstrated the failure of the in vivo $2 \mathrm{~b}_{(18-111)}$-AGO-dependent suppression of the host degradation of CMV RNAs in the absence of $2 \mathrm{~b}$ dsRNA binding activity.

In summary, although the silencing suppression activity of $2 \mathrm{~b}$ relies on its dsRNA binding capacity and is independent of its interaction with AGO (Duan et al., 2012), we found that in the context of virus infection, the $2 \mathrm{~b}-\mathrm{AGO}$ interaction was indispensable for interference with RDR-dependent antiviral silencing in Arabidopsis, and the effect was remarkable in the presence of the $2 b$ dsRNA-binding activity. The $2 b$ dsRNAbinding activity was essential for virulence, probably being related to its effect on the alteration of miR159-regulated transcript levels (Du et al., 2014b). However, in agreement with the dual edge of VSR in the virus-host interactions (Zhao et al., 2016), the $2 \mathrm{~b}$ protein exerted a precise effect on the regulation of balance between virus accumulation and virulenceinduced damage to the host. Binding to AGO proteins might weaken the nucleus/nucleolus localization of $2 b$ and inhibit the RDR-dependent degradation of viral RNAs in the cytoplasm, presumably to maximize the benefit for the virus. The multiple biochemical properties of the $2 b$ protein exerted essential roles in diverse silencing suppressor activities, which cooperatively or independently contributed to the accumulation and virulence of viral RNAs.

\section{AUTHOR CONTRIBUTIONS}

$\mathrm{HG}, \mathrm{CD}$, and YF conceived the study and designed the research. YF and JZ performed molecular work. YF, JZ, and SL performed the sampling and analyzed the data. SW assisted construction and infection. HG, YF, and JZ wrote the manuscript and discussed the results and all the authors commented on the manuscript.

\section{FUNDING}

This study was supported by the Ministry of Science and Technology (2014CB138402) and the Natural Science Foundation of China (No.91519327).

\section{ACKNOWLEDGMENTS}

We thank Dr. Shou-Wei Ding for $r d r 1 / 6$ Arabidopsis mutant seeds and Dr. Xian-Bing Wang for anti-2b antiserum.

\section{SUPPLEMENTARY MATERIAL}

The Supplementary Material for this article can be found online at: http://journal.frontiersin.org/article/10.3389/fmicb. 2016.01329 


\section{REFERENCES}

Axtell, M. J., Jan, C., Rajagopalan, R., and Bartel, D. P. (2006). A two-hit trigger for siRNA biogenesis in plants. Cell 127, 565-577. doi: 10.1016/j.cell.2006.09.032

Baulcombe, D. (2005). RNA silencing. Trends Biochem. Sci. 30, 290-293. doi: 10.1016/j.tibs.2005.04.012

Baulcombe, D.C. (2007). Molecular biology. Amplified silencing. Science 315, 199-200. doi: 10.1126/science.1138030

Chen, H.-Y., Yang, J., Lin, C., and Yuan, Y. A. (2008). Structural basis for RNAsilencing suppression by Tomato aspermy virus protein 2b. EMBO Rep. 9, 754-760. doi: 10.1038/embor.2008.118

Dalmay, T., Hamilton, A., Rudd, S., Angell, S., and Baulcombe, D. C. (2000). An RNA-dependent RNA polymerase gene in Arabidopsis is required for posttranscriptional gene silencing mediated by a transgene but not by a virus. Cell 101, 543-553. doi: 10.1016/S0092-8674(00) 80864-8

Diaz-Pendon, J. A., Li, F., Li, W. X., and Ding, S. W. (2007). Suppression of antiviral silencing by cucumber mosaic virus $2 \mathrm{~b}$ protein in Arabidopsis is associated with drastically reduced accumulation of three classes of viral small interfering RNAs. Plant Cell 19, 2053-2063. doi: 10.1105/tpc.106. 047449

Ding, S. W., Anderson, B. J., Haase, H. R., and Symons, R. H. (1994). New overlapping gene encoded by the cucumber mosaic virus genome. Virology 198, 593-601.

Ding, S.-W., Li, W.-X., and Symons, R. H. (1995). A novel naturally occurring hybrid gene encoded by a plant RNA virus facilitates long distance virus movement. EMBO J. 14, 5762-5772.

Dong, K., Wang, Y., Zhang, Z., Chai, L. X., Tong, X., Xu, J., et al. (2016). Two amino acids near the $\mathrm{N}$-terminus of Cucumber mosaic virus $2 \mathrm{~b}$ play critical roles in the suppression of RNA silencing and viral infectivity. Mol. Plant Pathol. 17, 173-183. doi: $10.1111 / \mathrm{mpp} .12270$

Du, Z., Chen, A., Chen, W., Liao, Q., Zhang, H., Bao, Y., et al. (2014a). Nuclear-cytoplasmic partitioning of cucumber mosaic virus protein $2 \mathrm{~b}$ determines the balance between its roles as a virulence determinant and an RNA-silencing suppressor. J. Virol. 88, 5228-5241. doi: 10.1128/jvi.00 284-14

Du, Z., Chen, A., Chen, W., Westwood, J. H., Baulcombe, D. C., and Carr, J. P. (2014b). Using a viral vector to reveal the role of MicroRNA159 in disease symptom induction by a severe strain of Cucumber mosaic virus. Plant Physiol. 164, 1378-1388. doi: 10.1104/pp.113. 232090

Duan, C. G., Fang, Y. Y., Zhou, B. J., Zhao, J. H., Hou, W. N., Zhu, H., et al. (2012). Suppression of Arabidopsis ARGONAUTE1-mediated slicing, transgene-induced RNA silencing, and DNA methylation by distinct domains of the Cucumber mosaic virus $2 \mathrm{~b}$ protein. Plant Cell 24, 259-274. doi: 10.1105/tpc.111.092718

Fernández, A., Guo, H. S., Sáenz, P., Simón-Buela, L., Gómez de Cedrón, M., and García, J. A. (1997). The motif V of plum pox potyvirus CI RNA helicase is involved in NTP hydrolysis and is essential for virus RNA replication. Nucleic Acids Res. 25, 4474-4480.

Garcia-Ruiz, H., Takeda, A., Chapman, E. J., Sullivan, C. M., Fahlgren, N., Brempelis, K. J., et al. (2010). Arabidopsis RNA-dependent RNA polymerases and dicer-like proteins in antiviral defense and small interfering RNA biogenesis during turnip mosaic virus infection. Plant Cell 22, 481-496. doi: 10.1105/tpc.109.073056

González, I., Martinez, L., Rakitina, D. V., Lewsey, M. G., Atencio, F. A., Llave, C., et al. (2010). Cucumber mosaic virus $2 \mathrm{~b}$ protein subcellular targets and interactions: their significance to RNA silencing suppressor activity. Mol. Plant Microbe Interact. 23, 294-303. doi: 10.1094/MPMI-2 3-3-0294

González, I., Rakitina, D., Semashko, M., Taliansky, M., Praveen, S., Palukaitis, P., et al. (2012). RNA binding is more critical to the suppression of silencing function of Cucumber mosaic virus $2 \mathrm{~b}$ protein than nuclear localization. RNA 18, 771-782. doi: 10.1261/rna.031260.111

Goto, K., Kobori, T., Kosaka, Y., Natsuaki, T., and Masuta, C. (2007). Characterization of silencing suppressor $2 \mathrm{~b}$ of Cucumber mosaic virus based on examination of its small RNA-binding abilities. Plant Cell Physiol. 48, 1050-1060. doi: 10.1093/pcp/pcm074
Guo, H. S., and Ding, S. W. (2002). A viral protein inhibits the long range signaling activity of the gene silencing signal. EMBO J. 21, 398-407. doi: 10.1093/emboj/21.3.398

Hamera, S., Song, X., Su, L., Chen, X., and Fang, R. (2012). Cucumber mosaic virus suppressor $2 \mathrm{~b}$ binds to AGO4-related small RNAs and impairs AGO4 activities. Plant J. 69, 104-115. doi: 10.1111/j.1365-313X.2011.04774.x

Hou, W. N., Duan, C. G., Fang, R. X., Zhou, X. Y., and Guo, H. S. (2011). Satellite RNA reduces expression of the $2 \mathrm{~b}$ suppressor protein resulting in the attenuation of symptoms caused by Cucumber mosaic virus infection. Mol. Plant Pathol. 12, 595-605. doi: 10.1111/j.1364-3703.2010. 00696.x

Li, F., Huang, C., Li, Z., and Zhou, X. (2014). Suppression of RNA silencing by a plant DNA virus satellite requires a host calmodulinlike protein to repress RDR6 expression. PLoS Pathog. 10:e1003921. doi: 10.1371/journal.ppat.1003921

Lucy, A. P., Guo, H. S., Li, W. X., and Ding, S. W. (2000). Suppression of posttranscriptional gene silencing by a plant viral protein localized in the nucleus. EMBO J. 19, 1672-1680. doi: 10.1093/emboj/19.7.1672

Meister, G., and Tuschl, T. (2004). Mechanisms of gene silencing by double-stranded RNA. Nature 431, 343-349. doi: 10.1038/nature 02873

Palukaitis, P., and Garcia-Arenal, F. (2003). Cucumoviruses. Adv. Virus Res. 62, 241-323. doi: 10.1016/S0065-3527(03)62005-1

Peragine, A., Yoshikawa, M., Wu, G., Albrecht, H. L., and Poethig, R. S. (2004). SGS3 and SGS2/SDE1/RDR6 are required for juvenile development and the production of trans-acting siRNAs in Arabidopsis. Genes Dev. 18, 2368-2379. doi: $10.1101 /$ gad.1231804

Qu, F. (2010). Antiviral role of plant-encoded RNA-dependent RNA polymerases revisited with deep sequencing of small interfering RNAs of virus origin. Mol. Plant Microbe Interact. 23, 1248-1252. doi: 10.1094/mpmi-06-1 0-0124

Qu, F., Ye, X., Hou, G., Sato, S., Clemente, T. E., and Morris, T. J. (2005). RDR6 has a broad-spectrum but temperature-dependent antiviral defense role in Nicotiana benthamiana. J. Virol. 79, 15209-15217. doi: 10.1128/jvi.79.24.1520915217.2005

Schwach, F., Vaistij, F. E., Jones, L., and Baulcombe, D. C. (2005). An RNA-dependent RNA polymerase prevents meristem invasion by potato virus $\mathrm{X}$ and is required for the activity but not the production of a systemic silencing signal. Plant Physiol. 138, 1842-1852. doi: 10.1104/pp.105. 063537

Schwinghamer, M. W., and Symons, R. H. (1975). Fractionation of cucumber mosaic virus RNA and its translation in a wheat embryo cell-free system. Virology 63, 252-262.

Shi, B.-J., Palukaitis, P., and Symons, R. H. (2002). Differential virulence by strains of Cucumber mosaic virus is mediated by the $2 b$ Gene. Mol. Plant Microbe Interact. 15, 947-955. doi: 10.1094/MPMI.2002.15.9.947

Vaistij, F. E., and Jones, L. (2009). Compromised virus-induced gene silencing in RDR6-deficient plants. Plant Physiol. 149, 1399-1407. doi: 10.1104/pp.108.132688

Wang, J., Yu, W., Yang, Y., Li, X., Chen, T., Liu, T., et al. (2015). Genome-wide analysis of tomato long non-coding RNAs and identification as endogenous target mimic for microRNA in response to TYLCV infection. Sci. Rep. 5:16946. doi: $10.1038 /$ srep 16946

Wang, X. B., Wu, Q., Ito, T., Cillo, F., Li, W. X., Chen, X., et al. (2010). RNAi-mediated viral immunity requires amplification of virus-derived siRNAs in Arabidopsis thaliana. Proc. Natl. Acad. Sci. U.S.A. 107, 484-489. doi: 10.1073/pnas.0904086107

Wu, H. J., Wang, Z. M., Wang, M., and Wang, X. J. (2013). Widespread long noncoding RNAs as endogenous target mimics for MicroRNAs in plants. Plant Physiol. 161, 1875-1884. doi: 10.1104/pp.113.215962

Xu, A., Zhao, Z., Chen, W., Zhang, H., Liao, Q., Chen, J., et al. (2013). Selfinteraction of the cucumber mosaic virus $2 \mathrm{~b}$ protein plays a vital role in the suppression of RNA silencing and the induction of viral symptoms. Mol. Plant Pathol. 14, 803-812. doi: 10.1111/mpp.12051

Ying, X. B., Dong, L., Zhu, H., Duan, C. G., Du, Q. S., Lv, D. Q., et al. (2010). RNA-dependent RNA polymerase 1 from Nicotiana tabacum suppresses RNA silencing and enhances viral infection in Nicotiana benthamiana. Plant Cell 22, 1358-1372. doi: 10.1105/tpc.109.072058 
Zhang, X., Yuan, Y. R., Pei, Y., Lin, S. S., Tuschl, T., Patel, D. J., et al. (2006). Cucumber mosaic virus-encoded $2 \mathrm{~b}$ suppressor inhibits Arabidopsis Argonaute1 cleavage activity to counter plant defense. Genes Dev. 20, 3255-3268. doi: 10.1101/gad.1495506

Zhao, J.-H., Hua, C.-L., Fang, Y.-Y., and Guo, H.-S. (2016). The dual edge of RNA silencing suppressors in the virus-host interactions. Curr. Opin. Virol. 17, 39-44. doi: 10.1016/j.coviro.2015.12.002

Zhu, Q.-H., Stephen, S., Taylor, J., Helliwell, C. A., and Wang, M.-B. (2014). Long noncoding RNAs responsive to Fusarium oxysporum infection in Arabidopsis thaliana. New Phytol. 201, 574-584. doi: 10.1111/nph.12537
Conflict of Interest Statement: The authors declare that the research was conducted in the absence of any commercial or financial relationships that could be construed as a potential conflict of interest.

Copyright $\odot 2016$ Fang, Zhao, Liu, Wang, Duan and Guo. This is an open-access article distributed under the terms of the Creative Commons Attribution License (CC $B Y)$. The use, distribution or reproduction in other forums is permitted, provided the original author(s) or licensor are credited and that the original publication in this journal is cited, in accordance with accepted academic practice. No use, distribution or reproduction is permitted which does not comply with these terms. 